\title{
Self-Efficacy Is Mainly Genetic, Not Learned: A Multiple-Rater Twin Study on the Causal Structure of General Self-Efficacy in Young People
}

Trine Waaktaar ${ }^{1}$ and Svenn Torgersen ${ }^{1,2}$

${ }^{1}$ Centre for Child and Adolescent Mental Health, Oslo, Norway

${ }^{2}$ Department of Psychology, University of Oslo, Oslo, Norway

Social learning theory postulates that self-efficacy is learned through the person's interaction with his/her physical and social environment. In this genetically informative, population-based, multi-informant study of 1,394 adolescent twin pairs, self-efficacy was modeled as one latent psychometric self-efficacy factor with genetic and environmental effects common to all informants, as well as for effects specific for each informant. The results showed that $75 \%$ of variation in self-efficacy was due to genetic factors. Non-shared environmental causes explained the remaining $25 \%$ of the variance in the latent factor, with no effect of common environment. Some informant-specific effects were also found. The present study challenges the theoretical assumption of learning as the dominant etiological factor behind self-efficacy in young people.

Keywords: general self-efficacy, adolescents, twin study, heritability, young people, rater specificity

Although natural constituents of human life, people often find transitional phases between developmental stages challenging and stressful. Adolescence is characterized by change in personal and social as well as physical domains. The ways in which young people handle the developmental tasks inherent in this phase can be decisive for their further progress into adult life. Perceived self-efficacy has been proposed as one important personal characteristic influencing adaptation in youth (Caprara et al., 2010).

Self-efficacy is about the ways in which people think about their abilities to accomplish goals and influence events with importance for their lives (Bandura, 1994). A wide range of self-efficacy beliefs have been identified in relation to specific tasks or realms, such as cannabis refusal (Young et al., 2012) and safer sex (Widman et al., 2012). However, various efficacy beliefs are often related within persons (Scholz et al., 2002), and factor analyses of questionnaire data with children and young people have yielded support for a general self-efficacy factor (Pastorelli et al., 2001).

Empirical studies have found self-efficacy to be related to a series of important indicators of youth's adaptation. Thus, higher self-efficacy was negatively associated with weight/eating difficulties in adolescent girls (Steele et al., 2011), and positively related to health self-care ability (Nouwen et al., 2009), prosociality (Alessandri et al., 2009), and academic achievement (Carroll et al., 2009). Further, self-efficacy seems to have a significant role as a moderator between putative risk factors and outcomes (Benight \& Bandura, 2004; Farrell et al., 2010), and as a mediating variable between several types of risk and mental and physical health outcomes in young people (Alvy et al., 2011).

The concept of self-efficacy originates from social learning theory (Bandura, 1977), based on which it has been postulated that people build their perception of self-efficacy on four sources of information: experience of own performance accomplishments; vicarious experiences of observing successful efforts made by others; verbal persuasion that one is capable of managing one's challenges; and internal physical arousal states that provide cues about one's personal level of anxiety and stress vulnerability. Thus, theoretically, self-efficacy is supposed to be learned through the individual's interaction with herself and her physical and social environment. However, there are some

RECEIVED 8 January 2013; ACCEPTED 18 March 2013. First published online 22 April 2013.

ADDRESS FOR CORRESPONDENCE: Trine Waaktaar, Centre for Child and Adolescent Mental Health, Oslo, RBUP Eastern and Southern Norway, 4623 Nydalen, 0405 Oslo, Norway. E-mail: trine.waaktaar@r-bup.no 
indications that there are also genetic influences behind individual differences in self-efficacy.

In a study focusing on the relationship between academic self-efficacy, IQ, and academic performance in 7to 10-year-old twins, Greven et al. (2009) reported that around half of the variation in perceived academic selfefficacy was due to additive heritability factors. Bullers and Prescott (2001) found moderate genetic effects in a twin study of 'perceived control' among adult women, although the non-shared environmental effects explained the larger part of variation in their study. These are the only previous studies known to us that include information about genetic influences in perceived self-efficacy. Twin studies of conceptually related traits in adolescents, such as self-acceptance (Gigantesco et al., 2011), trait resilience (Waaktaar \& Torgersen, 2012b), and executive self (Neiss et al., 2005) have reported moderate to high heritability estimates, indicating that adaptive characteristics may not be all environmental in their causal structure.

The aim of the present study was to investigate the relative contribution of genetic and environmental etiological sources in explaining variability of general self-efficacy in youths. Data was collected in a population-based survey of seven national Norwegian cohorts of monozygotic (MZ) and dizygotic (DZ) adolescent twins of both sexes reared together. A multi-informant (mothers, fathers, and twins' self-ratings) approach was chosen, which has the advantage of offering an error-free estimate of the relative impact of common etiological sources as well as to sources specific for each informant on the trait in focus (Bartels et al., 2007). The primary hypothesis, based on heritability estimates reported in earlier studies on related constructs, was that perceived self-efficacy would be moderately heritable. Although there are reported differences in the amount of self-efficacy beliefs between the sexes (Choi, 2004), no previous studies existed that could provide reasonable basis for formulating a hypothesis on the existence of sex differences in the sizes of genetic and environmental estimates on perceived self-efficacy.

\section{Materials and Methods}

\section{Participants and Procedure}

The sample consisted of 1,394 twin pairs (25.5\% of total twin population in the relevant cohorts, $56.2 \%$ of available pairs) and parents who participated in the study based on a mailed invitation to seven full cohorts of twins born between 1988 and 1994. Twin status and addresses were provided by the national Norwegian Medical Birth Registry. Twins, mothers, and fathers answered paper-andpencil inventories that were returned by mail. For sample sizes for each zygosity group, see Table 1 . More details on sample characteristics, including study attrition and procedure, can be found in Waaktaar and Torgersen (2012b).

\begin{tabular}{|c|c|c|c|c|}
\hline \multicolumn{5}{|c|}{$\begin{array}{l}\text { Descriptive Data of Youths' Self-Efficacy Scores Rated by } \\
\text { Mothers, Fathers, and Twins by Zygosity Group }\end{array}$} \\
\hline & Informant & $N$ & Mean & $S D$ \\
\hline \multirow{3}{*}{ MZM } & Mother & 430 & 32.7 & 7.61 \\
\hline & Father & 318 & 32.0 & 7.03 \\
\hline & Twins & 418 & 34.0 & 6.07 \\
\hline \multirow[t]{3}{*}{ MZF } & Mother & 579 & 33.9 & 7.50 \\
\hline & Father & 420 & 33.9 & 6.79 \\
\hline & Twins & 600 & 33.9 & 6.74 \\
\hline \multirow[t]{3}{*}{ DZM } & Mother & 385 & 33.1 & 7.60 \\
\hline & Father & 287 & 32.0 & 7.57 \\
\hline & Twins & 378 & 34.1 & 6.41 \\
\hline \multirow[t]{3}{*}{ DZF } & Mother & 460 & 34.0 & 7.84 \\
\hline & Father & 331 & 33.3 & 6.84 \\
\hline & Twins & 478 & 33.3 & 6.54 \\
\hline \multirow[t]{3}{*}{ DOS } & Mother & 783 & 33.4 & 7.16 \\
\hline & Father & 583 & 32.2 & 7.17 \\
\hline & Twins & 757 & 34.5 & 6.28 \\
\hline
\end{tabular}

Note: $\mathrm{MZM}=$ monozygotic males; $\mathrm{MZF}=$ monozygotic females; DZM = dizygotic males, DZF = dizygotic females, DOS = dizygotic twins with opposite sex.

\section{Measures}

General self-efficacy. Self-efficacy was measured by means of the Children's Perceived Self-Efficacy Scale by Pastorelli et al. (2001). The scale was translated into Norwegian language by the study researchers and later back-translated by a Norwegian/English bilingual psychologist. All items began with the sentence 'How well can you..., and twins' self-rating forms and parental forms were identical except from the substitution of 'I' and 'me' in the twins' forms with 'The twin' and 'his/her' in the parental forms. In the present study, 12 items sampled from academic, social, and self-regulatory domains were employed. Items were scored on a 5-point scale (coded 0-4), from 'not at all well' to 'very well, yielding a potential minimum score of 0 and maximum score of 48. General self-efficacy scores as assessed by each rater were generated as the sum scores of the 12 items. Final inter-item reliability Cronbach's alpha in the mothers' subscale scores was 0.86 . The corresponding alpha coefficient of the fathers' scores was 0.86 and that for the twins' scores 0.79 .

Zygosity. Zygosity was determined through a combination of a questionnaire testing for twin physical similarity that was answered by the total sample, and DNA secured through cheek swabs from 15\% of the sample (Waaktaar \& Torgersen, 2012b). Twins who were not tested on DNA were allocated to zygosity group by means of discriminant analysis of the questionnaire data from each twin, mother, and father. The misclassification following this procedure based on comparisons between DNA and the questionnaire data was estimated to be less than $2 \%$.

\section{Data Analyses}

Data preparation. Because of significant effects of age and sex on the mean structure and negative skewness on 
several of the scales, data was residualized and square roottransformed prior to genetic analyses. Preliminary univariate analyses for each informant separately using a correlated factors model showed no deviation from the basic assumption of equality of means and variances across twins and zygosity groups in any of the informants' scores (results of data preparation analyses are available from the first author upon request). All data analyses were performed using the open source statistical software package R, version 2.14.1 (R Development Core Team, 2011). All genetic modeling analyses were performed using the OpenMx version 1.2.3 (Boker et al., 2011), a package within the $\mathrm{R}$ software for fitting structural equation models to observed data.

Genetic modeling. The classic twin model rests on the assumption that while MZ twins share practically all their genetic makeup, DZ twins have on average $50 \%$ of their segregating genes in common. Thus, if variation in a certain phenotype were caused by the additive effect of several genes (A), then the correlation between DZ twins on that phenotype should be half the size of the MZ correlation. Phenotypic DZ correlations above half of $\mathrm{MZ}$ correlation must be caused by common environmental factors (C) acting to make the twins in the same family more similar on the specific trait. Any relative difference in correlation between DZ and $\mathrm{MZ}$ below $50 \%$ within this model would be attributed to the interactive effect of various genes (D) within a specific locus (dominance) or across different loci (episasis). In the classic twin design the $\mathrm{C}$ and $\mathrm{D}$ are overlapping and thus are not testable within the same model. Moreover, any difference between $\mathrm{MZ}$ twins would either result from environmental factors affecting each twin separately (named non-shared environmental factors) (E) and/or measurement error. Whereas in the univariate case, the real nonshared effects cannot be separated from the measurement error, multivariate data allow for testing of models that yield error-free estimates of $\mathrm{E}$ (such as the multivariate psychometric model employed here; see below for more on this model). The validity of the twin model rests on two further assumptions: (1) no assortative mating for the phenotype measured; and (2) MZ and DZ twins are equally exposed to the relevant environmental stimuli for the trait studied. There is generally little empirical evidence of violations of these assumptions (Bulik et al., 2000; Neale et al., 1998).

The etiological structure behind the twin associations was analyzed using a biometrical modeling approach (Neale \& Cardon, 1992) where covariances based on raw data are fitted to a structural equation model through maximum likelihood estimation (FIML). Alternative models were compared using the Akaike information criterion (AIC; Akaike, 1987). This fit statistic takes into account the overall fit as well as the parsimony of the model, and lower numbers signify improved model fit.
Model fitting. The genetic models employed in the present study were all variants of the psychometric common factor model (Rijsdijk \& Sham, 2002). The full multivariate model with three informants is shown in Figure 1.

The psychometric model assumes that variation in the informants' scores can be partitioned into a set of common $\mathrm{A}, \mathrm{C}$, and $\mathrm{E}$ sources explaining the variance of a common latent psychometric factor in addition to A, C, and E sources that are specific for each informant (Baker et al., 2007; Bartels et al., 2007). Thus, this model assumes that not all variations between informants may be due to measurement error or rater bias, and allows for the possibility for mothers, fathers, and adolescents to provide substantive additional information about an adolescent's behavior. Several studies have demonstrated the relevance of such a model for characteristics of young people assessed by multiple raters (Scourfield et al., 2004; Waaktaar \& Torgersen, 2012a).

An important asset of the psychometric model is that the common psychometric factor will be unaffected by informant-specific bias and measurement error. Thus, the non-shared environmental pathway on the common factor includes only effective environmental influences that make the twins different from each other. Measurement error is, in this model, contained together with informant-specific environmental effects within the non-shared environmental pathways on the informant-specific self-efficacy factors (Neale \& Cardon, 1992). This implies that the common effects on the latent psychometric factor will provide highly reliable estimates of the effect of different etiological sources on perceived general self-efficacy in adolescents.

\section{Results \\ Descriptive}

Group means and standard deviations. Table 1 shows sample means and standard deviations of (unresidualized) scale scores by gender, zygosity groups, and informants. There were several significant differences between informants' scores in all zygosity groups, with higher scores generally endorsed by twins and mothers than by fathers, and with girls scoring higher on self-efficacy than boys.

Correlation structure. The correlation matrix in Table 2 gives the first impression of the genetic structure within the data. Correlations were generated through ML estimation, and were thus built on the same logic that constitutes the basis for the later twin models. The cross-twin withininformant $\mathrm{MZ}$ correlations (diagonal entries) were clearly exceeding those of the DZ group for all informants and both sexes, a pattern that was replicated in the cross-twin, crossinformant correlations (off diagonal entries). Thus, genetic effects were indicated both in the scores of each informant separately and in the associations between informants. The $\mathrm{MZ} / \mathrm{DZ}$ correlation ratio was generally above 0.5 , signifying the possibility of some shared environmental effects. 
1.0

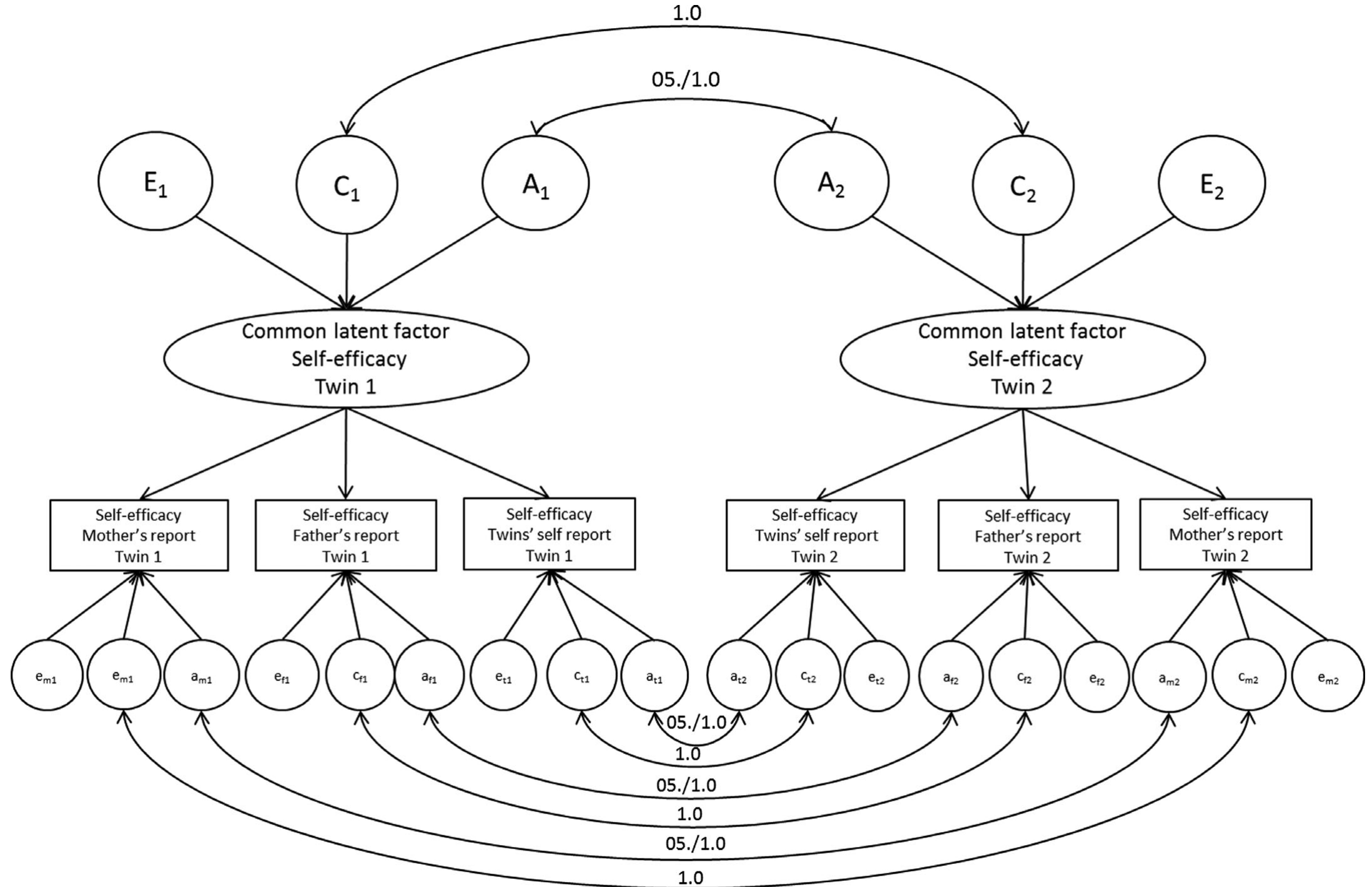

\section{FIGURE 1}

Full psychometric model. $\mathrm{A}=$ common additive genetic factor; $\mathrm{a}=$ informant-specific additive genetic factor; $\mathrm{C}=$ common shared environmental factor; $\mathrm{c}=$ informant-specific shared environmental factor; $E=$ common non-shared environmental factor; $e=$ informant-specific non-shared environmental factor. Subscripts: $m=$ mothers' scores; $f=$ fathers' scores; $t=$ twins' self-ratings: $1=$ twin $1 ; 2=$ twin 2 . Arrows marked 1.0 or $0.5 / 1.0$ signify the twin correlations of DZ and MZ pairs, respectively, as assumed in the model. 
TABLE 2

Estimated Twin Correlations Across Sex for Different Informant Scores and Two Zygosity Groups

\begin{tabular}{|c|c|c|c|c|c|c|c|c|c|c|c|c|c|c|}
\hline & & \multicolumn{4}{|c|}{ Within-person correlations } & \multicolumn{9}{|c|}{$\begin{array}{l}\text { Cross-person correlations: within-informant (diagonal) and cross-informant } \\
\text { (off diagonals) }\end{array}$} \\
\hline & & \multirow[b]{2}{*}{ Mo } & \multirow[b]{2}{*}{$\mathrm{Fa}$} & & & \multicolumn{3}{|c|}{ Male pairs } & \multicolumn{3}{|c|}{ Female pairs } & \multicolumn{3}{|c|}{ Opposite sex pairs } \\
\hline & & & & & & Mo & $\mathrm{Fa}$ & Tw & Mo & $\mathrm{Fa}$ & Tw & Mo & $\mathrm{Fa}$ & Tw \\
\hline & & & & Mother & $\mathrm{MZ}$ & 0.729 & & & 0.600 & & & & & \\
\hline & & & & & $\mathrm{DZ}$ & 0.376 & & & 0.428 & & & 0.285 & & \\
\hline \multirow[t]{2}{*}{ Father } & Males & 0.568 & & Father & $\mathrm{MZ}$ & 0.491 & 0.689 & & 0.356 & 0.550 & & & & \\
\hline & Females & 0.524 & & & $\mathrm{DZ}$ & 0.181 & 0.385 & & 0.233 & 0.301 & & 0.068 & 0.202 & \\
\hline \multirow{2}{*}{ Twins } & Males & 0.347 & 0.305 & Twins & $\mathrm{MZ}$ & 0.284 & 0.233 & 0.243 & 0.294 & 0.216 & 0.410 & & & \\
\hline & Females & 0.357 & 0.311 & & DZ & 0.135 & 0.107 & 0.143 & 0.236 & 0.175 & 0.204 & 0.124 & 0.126 & 0.128 \\
\hline
\end{tabular}

Note: $M Z=$ monozygotic pairs; $D Z=$ dizygotic pairs, $M o=$ mothers' ratings; Fa = fathers' ratings; Tw $=$ twins' self-ratings.

TABLE 3

Fit Statistics for Different Models Under the Psychometric ACE Model Without Sex Differences

\begin{tabular}{|c|c|c|c|c|c|c|c|c|c|c|c|c|c|c|c|c|}
\hline \multirow[b]{2}{*}{$\#$} & \multicolumn{3}{|c|}{ Latent } & \multicolumn{3}{|c|}{ Mothers } & \multicolumn{3}{|c|}{ Fathers } & \multicolumn{3}{|c|}{ Twins } & \multirow[b]{2}{*}{$\Delta-2 \mathrm{LL}$} & \multirow[b]{2}{*}{$\Delta d f$} & \multirow[b]{2}{*}{$p$} & \multirow[b]{2}{*}{$\triangle \mathrm{AIC}$} \\
\hline & A & C & $E$ & $a$ & $c$ & $\mathrm{e}$ & $\mathrm{a}$ & c & c & $a$ & $c$ & $\mathrm{e}$ & & & & \\
\hline I & + & + & + & + & + & + & + & + & + & + & + & + & - & - & - & - \\
\hline II & - & + & + & + & + & + & + & + & + & + & + & + & 64.48 & 1 & 0 & 62.48 \\
\hline III & + & + & + & - & + & + & - & + & + & - & + & + & 64.07 & 3 & 0 & 58.07 \\
\hline IV & - & + & + & - & + & + & - & + & + & - & + & + & 165.36 & 4 & 0 & 157.36 \\
\hline V & + & - & + & + & + & + & + & + & + & + & + & + & 0 & 1 & 1 & $-2^{*}$ \\
\hline VI & + & + & + & + & - & + & + & - & + & + & - & + & 6.8 & 3 & .08 & 0.8 \\
\hline VII & + & - & + & + & - & + & + & - & + & + & - & + & 7.6 & 4 & .11 & -0.39 \\
\hline VIII & + & + & - & + & + & + & + & + & + & + & + & + & 64.48 & 1 & 0 & 62.48 \\
\hline IX & - & - & + & + & + & + & + & + & + & + & + & + & 286.17 & 2 & 0 & 282.17 \\
\hline$x$ & - & - & - & + & + & + & + & + & + & + & + & + & 2765.34 & 3 & 0 & 2759.33 \\
\hline
\end{tabular}

Note: *Best fitting model.

$A=$ common additive genetic factor; $C=$ common shared environmental factor; $E=$ common non-shared environmental factor; $a=$ informant-specific additive genetic factor; $c=$ informant-specific shared environmental factor; e = informant-specific non-shared environmental factor.

Consequently, the ACE model would seem more adequate than the ADE model in the subsequent genetic modeling analyses. There were only minor differences in the size of the $\mathrm{MZ} / \mathrm{DZ}$ ratio between correlations of the same-sex boys and the same-sex girls, and the correlations between the same-sex DZ twins were not of markedly smaller scale than correlations for opposite-sex DZ twins. Thus, based on the cursory view of the correlation matrix, any sex-specific effects were not likely to be of large scale. The cross-informant within-person correlations were in medium range, indicating informant-specific as well as common effects.

Multivariate model testing. The full ACE psychometric model with heterogeneity (allowing for sex differences in the estimates) was chosen as the baseline model. Compared with the full model, the ACE model with no sex limitation did not result in significantly worse fit $(\Delta-2 \mathrm{LL}=1.28, \Delta d f=$ $15, p=1)$. Hence, the psychometric ACE homogeneity model was chosen as a starting point for the subsequent testing of more stringent models. Results of these analyses are shown in Table 3.

In this series of submodel testing, each common and specific etiological factor was dropped individually and then together from the full ACE model. The results showed that the common $\mathrm{C}$ could be removed without any significant drop in fit compared to the full psychometric model. The psychometric ACE model with one common latent factor and no common $\mathrm{C}$ was also the most parsimonious model as judged by the lowest Akaike information criterion (AIC) value. Inspection of the path estimates within this model indicated very low values on specific A in the mothers' scores and specific $C$ in the fathers' and twins' scores, and with confidence intervals including the value of zero. Further testing showed that these paths could be dropped without significant reduction of the fit as compared to the $\mathrm{A}_{\mathrm{c}} \mathrm{E}_{\mathrm{c}} \mathrm{A}_{\mathrm{s}} \mathrm{C}_{\mathrm{s}} \mathrm{E}_{\mathrm{s}}$ model $(\Delta-2 \mathrm{LL}=2.29, \Delta d f=3, p=.51)$, leading us to the preferred model.

Figure 2 shows the standardized and squared path estimates in the final model with confidence intervals. The results showed that general self-efficacy in youths as measured by three informants could be modeled by means of a common latent psychometric factor with a pronounced additive genetic component accounting for three-quarters of the common factor variance. The remaining one-quarter variance was attributable to (error-free) non-shared environmental effects. There was no shared environmental effect on the common factor in this model. The figure also shows that the effect of the common self-efficacy factor 


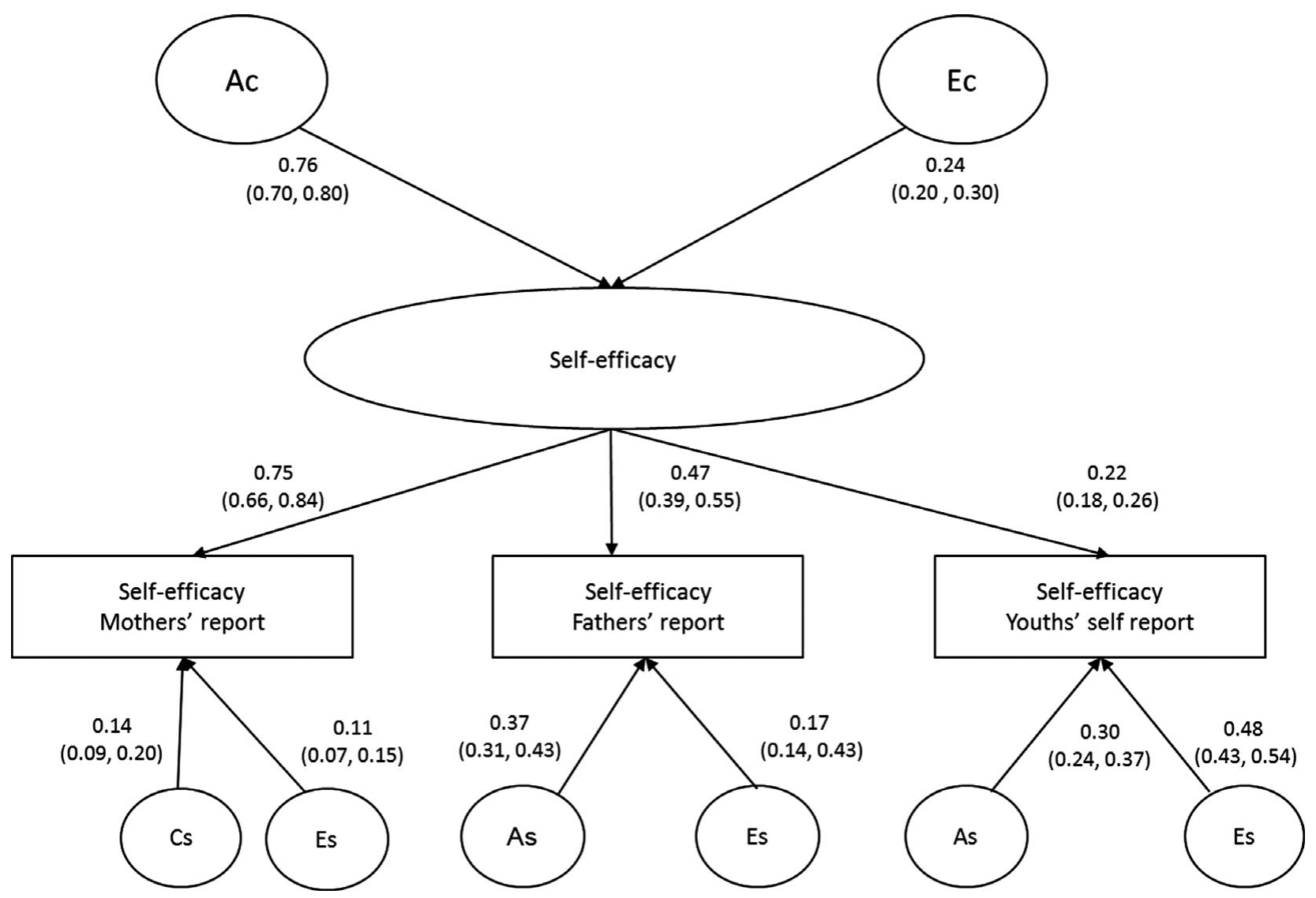

\section{FIGURE 2}

Final model with standardized and squared path estimates with confidence intervals. Ac = common additive genetic factor; As = informant-specific additive genetic factor; $\mathrm{Cc}=$ common shared environmental factor; Cs $=$ informant-specific shared environmental factor; Ec = common non-shared environmental factor; Es = informant-specific non-shared environmental factor.

was largest on the mothers' ratings, and somewhat smaller in the scores of the fathers' and twins' self-ratings (arrows pointing from the common factor to each of the informants' observed scores). The informant-specific additive genetic effects were strongest in the fathers' scores, while these effects were non-significant in the mothers' scores. There was a small but significant shared environmental effect within the mothers' scores that was not replicated in the scores of other informants. The informant-specific environmental effects (including random measurement error) were strongest in the twins' scores.

Table 4 presents the proportion of the variance in each informant's scores that was explained by common and raterspecific effects respectively.

As we can see in Table 4, the strongest genetic effect was found in the fathers' scores, of which about half of the genetic effects were related to factors specific for the fathers' reports. The remaining variance in the fathers' scores was explained by non-shared environmental effects, with a relatively high proportion (compared with the mothers' and youths' scores) contained within the error-free common factor E. Genetic effects also explained the majority of the variance in the mothers' scores. This maternal-reported genetic variance was fully contained within the common factor A. A small, shared environmental effect was specific for the mothers' scores only. Somewhat above one-quarter of the variance in the mothers' scores was explained by nonshared environmental effects. Of these, about one-third was attributable to the error-free common factor E. The lowest total genetic effects were found in the twins' self-ratings, where genetic and non-shared environmental effects each accounted for about half of the variance. The majority of the effects in the twins' self-ratings were rater-specific. This was particularly pronounced for the non-shared environmental factors where only $10 \%$ of the effect was contained within the error-free, common-factor, non-shared environmental estimate.

\section{Discussion}

The aim of this multi-informant twin study was to provide reliable estimates of the relative effect of genetic and environmental causes of variation in general self-efficacy in young people. Biometric analyses were based on an ACE 
TABLE 4

Variance Estimates in Final Model by Informant

\begin{tabular}{|c|c|c|c|c|c|c|c|c|c|}
\hline & $\begin{array}{l}\text { Total } \\
\text { heritability } \\
\left(\mathrm{h}^{2}\right)\end{array}$ & $\begin{array}{l}\text { Proportion } \\
\text { (\%) due to } \\
\mathrm{Ac}\end{array}$ & $\begin{array}{l}\text { Proportion } \\
\text { (\%) due to } \\
\text { As }\end{array}$ & $\begin{array}{l}\text { Total shared } \\
\text { environment } \\
\left(c^{2}\right)\end{array}$ & $\begin{array}{l}\text { Proportion } \\
\text { (\%) due to } \\
\text { Cc }\end{array}$ & $\begin{array}{l}\text { Proportion } \\
\text { (\%) due to } \\
\text { Cs }\end{array}$ & $\begin{array}{l}\text { Total non-shared } \\
\text { environment }\left(\mathrm{e}^{2}\right)\end{array}$ & $\begin{array}{l}\text { Proportion } \\
\text { (\%) due to } \\
\text { Ec }\end{array}$ & $\begin{array}{l}\text { Proportion } \\
\text { (\%) due to } \\
\text { Es }\end{array}$ \\
\hline Mothers & 0.57 & 100 & 0 & 0.14 & 0 & 100 & 0.29 & 62 & 38 \\
\hline Fathers & 0.72 & 49 & 51 & - & - & - & 0.28 & 40 & 60 \\
\hline Twins & 0.47 & 35 & 65 & & & & 0.53 & 10 & 90 \\
\hline
\end{tabular}

Note: $\mathrm{Ac}=$ common additive genetic factor; $\mathrm{As}=$ informant-specific additive genetic factor; $\mathrm{Cc}=$ common shared environmental factor; Cs = informant-specific shared environmental factor; Ec = common non-shared environmental factor; Es = informant-specific non-shared environmental factor.

common factors model approach, assuming that the covariation between different informants' scores for both sexes could be modeled as a latent psychometric general selfefficacy factor. Additive genetic and unique environmental factors were modeled to influence different informants' scores through the same mechanisms, but the model also allowed for additive genetic, shared, and non-shared environmental sources influencing each informant's scores specifically.

The results showed that additive genetic factors explained $75 \%$ of the variation in the common psychometric general self-efficacy factor. The remaining $25 \%$ of the variation in this factor was explained by unique, non-shared environmental effects. The impact of shared environmental sources on the common factor was non-significant. There were no significant sex differences in the estimates of the model.

This is the first twin study to our knowledge to report heritability estimates of general self-efficacy in adolescents. The genetic effects found in the present study clearly exceed those reported in two related studies. Greven et al. (2009) reported heritability estimates of around $50 \%$, based on selfratings of 'academic self-efficacy' in younger school children. A study on 'perceived control' in adult female twins by Bullers and Prescott (2001) yielded a heritability estimate of only about $16 \%$. One likely explanation for the markedly higher heritability found in the present study is that it may be due to the advantage of the multi-rater design, which is able to produce more reliable estimates than those based on any one single rater. In fact, the genetic effect in our study when based only on the twins' self-ratings was comparable with those reported by Greven et al. (2009). However, in our study, youths' self-ratings produced the lowest heritability estimates of all informants. Both parents' scores produced markedly higher estimates of heritability, with the fathers' scores being the highest $\left(\mathrm{h}^{2}=0.72\right)$. Thus, there is a reason to be cautious about basing heritability estimates on single raters.

The common shared environmental effects in the present study were non-significant. However, a shared environmental effect of $14 \%$ was specific for the mothers' scores. In the former studies by Greven et al. (2009) and Bullers and Prescott (2001), common environmental sources also reached very low estimates (2-15\%). This would indicate that there might be a weak, albeit significant, effect of shared environmental factors on self-efficacy, at least as detected by single informants. An alternative interpretation of this result in the mothers' scores could be some kind of rater bias acting on the mothers' scores to make DZ twins appear more alike. Because of the lack of any significant $\mathrm{C}$ in the scores of fathers and twins, testing of alternative rater bias models was not pursued.

The environmental effects on self-efficacy in the present study were primarily non-shared. The $25 \%$ non-shared effect on the latent self-efficacy factor implies that all environmental variations in the latent perceived general self-efficacy factor must have originated from sources that are unique for each twin within the same family (the error-free common $\mathrm{E}$ in the model). This is in accordance with what is found for the most complex human traits (Plomin et al., 2001). Generally, such effects are supposed to consist of events such as illness or accidents affecting one twin and not the other, or friendships unique to each twin. Among potential familial environmental influences within the family, only those that in effect would make twins within the same family different from one another on general self-efficacy could be of relevance. The informant-specific non-shared environmental effect $(11 \%, 17 \%$ and $48 \%$ for mothers, fathers and twins respectively) should be interpreted with care, as within these estimates are also contained any random measurement error. Thus, one could speculate whether the elevated specific $\mathrm{E}$ in the youths' self-ratings could contain some real - yet parentally unnoticed - element of differentiation going on between the twins. However, in the present model this effect could not be statistically separated from uncorrelated measurement error specific for the twins' scores, an effect that could plausibly be related to rater differences in maturity or motivation as compared with the parental scores.

\section{Limitations}

Some limitations should be kept in mind when evaluating the results of this study.

As noted by Turkheimer et al. (2005), the twins rearedtogether design may overestimate the effect of genetic influences and underestimate shared environmental influences because variables measured on the family level are modeled to be equal for both twins and thus cannot be separated into 
genetic and environmental components. Employing an alternative design, namely that of adoptive siblings, Buchanan et al. (2009) found significant shared environmental effects on the variance in several behavioral domains in adolescents. Although the shared environmental effect was generally low to moderate and differed markedly between domains, such results are important reminders of the importance of validating conclusions from twin studies with results from other types of genetically informative studies.

A clear advantage of a register-based study is that the actual size of the total population in the target cohorts is known, and, depending on the type of the register used, that also some causes of attrition (death of informants, family moving abroad) might be identified. However, such studies typically end up with lower participation rates than studies where the actual population size and distribution can only be estimated based on other statistical data. We would consider the participation rate in the present study (onequarter of the total population and about one-half of the available families) to be in line with what is to be expected in a modern Western society sample where the consent and participation of several family members - including adolescents - is required. However, representativity of results in relation to risk of selective attrition certainly needs to be considered. As published in an earlier article based on the same sample (Waaktaar \& Torgersen, 2012b), a comparison between level of education in the participating families to age equivalent levels for women and men within the total population indicated a possible selection bias in the participating families based on socioeconomic indicators. Differential heritability estimates across socioeconomic groups have been reported in genetically informative studies (South \& Krueger, 2011) as well as in groups with different exposure to various stressful conditions (Distel et al., 2011). Thus, the possibility that this type of bias may have influenced the heritability estimates in the present study cannot be ruled out.

Measurement invariance may be an issue in studies where different groups are being compared on measures of complex traits. In fact, one type of measurement noninvariance is demonstrated in the multiple raters' scores in the present study, expressed through the differences in latent factor loadings between informants assessing twins' general self-efficacy. In twin studies, measurement noninvariance on item level between zygosity groups may impact the estimates in studies based on sum scores (Neale et al., 2005). The problem of item-level non-invariance would be highest in the case of binary items. A full multivariate simultaneous analysis of measurement model and variance decomposition analytic approach would provide the most effective handling of the measurement invariance issue. There are indications from earlier studies on problem behaviors in young people that this kind of approach could yield even higher heritability estimates (van den Berg et al., 2007). For the target phenotype of general self- efficacy, the usefulness of analyses at this level of precision is questionable.

\section{Conclusion}

General self-efficacy in adolescents was measured by three informants (mothers, fathers, and the twins' self-ratings) and modeled by means of a common latent factor, with common genetic, shared, and non-shared environmental factors affecting the latent factor and additional genetic and environmental factors affecting each informant's scores. The latent general self-efficacy factor was highly genetically determined, with additive genetic effects explaining threequarters of the variance and non-shared environmental explaining the remaining one-quarter of the common factor variance. There were no significant shared environmental factors in general self-efficacy on the common latent factor. Some additional informant-specific genetic, shared environmental, and non-shared environmental effects were also found.

This study seriously challenges the basic theoretical etiological assumption that self-efficacy is learned through people's interaction with the environment. The present results indicate that individual differences in self-efficacy are mainly caused by genetic effects. Our heritability estimates are clearly exceeding what former genetically informative studies based on one single informant have suggested, which demonstrates that a multiple rater approach is important in the search for the etiological basis of adaptive traits in young people.

\section{Acknowledgments}

The present study was supported by grants from the Norwegian Research Council, grant number: 170089.

\section{References}

Akaike, H. (1987). Factor analysis and AIC. Psychometrika, 52, 317-332.

Alessandri, G., Caprara, G. V., Eisenberg, N., \& Steca, P. (2009). Reciprocal relations among self-efficacy beliefs and prosociality across time. Journal of Personality, 77, 1229-1259.

Alvy, L. M., McKirnan, D. J., Mansergh, G., Koblin, B., Colfax, G. N., Flores, S. A., . . Project, MIX Study Group. (2011). Depression is associated with sexual risk among men who have sex with men, but is mediated by cognitive escape and self-efficacy. AIDS Behavior, 15, 1171-1179.

Baker, L. A., Jacobson, K. C., Raine, A., Lozano, D. I., \& Bezdjian, S. (2007). Genetic and environmental bases of childhood antisocial behavior: A multi-informant twin study. Journal of Abnormal Psychology, 116, 219-235.

Bandura, A. (1977). Self-efficacy: Toward a unifying theory of behavioral change. Psychological Review, 84, 191-215.

Bandura, A. (1994). Self-efficacy. In V.S. Ramachaudran(Ed.), Encyclopedia of human behavior, vol. 4 (pp. 71-81). New York: Academic Press. (Reprinted from: H. Friedman (Ed.) 
(1998) Encyclopedia of mental health. San Diego, CA: Academic Press).

Bartels, M., Boomsma, D. I., Hudziak, J. J., Van Beijsterveldt, T. C. E. M., \& Van den Oord, E. J. C. G. (2007). Twins and the study of rater (dis)agreement. Psychological Methods, $12,451-466$.

Benight, C. C., \& Bandura, A. (2004). Social cognitive theory of post-traumatic recovery: The role of perceived self-efficacy. Behaviour Research and Therapy, 42, 1129-1148.

Boker, S., Neale, M., Maes, H., Wilde, M., Spiegel, M., Brick, T., ... Fox, J. (2011). OpenMx: An open source extended structural equation modeling framework. Psychometrika, 76, 306-317.

Buchanan, J. P., McGue, M., Keyes, M., \& Iacono, W. G. (2009). Are there shared environmental influences on adolescent behavior? Evidence from a study of adoptive siblings. $\mathrm{Be}$ havior Genetics, 39, 532-540.

Bulik, C. M., Sullivan, P. F., Wade, T. D., \& Kendler, K. S. (2000). Twin studies of eating disorders: A review. International Journal of Eating Disorders, 27, 1-20.

Bullers, S., \& Prescott, C. A. (2001). An exploration of the independent contributions of genetics, shared environment, specific environment, and adult roles and statuses on perceived control. Sociological Inquiry, 71, 145-163.

Caprara, G. V., Gerbino, M., Paciello, M., Di, G. L., \& Pastorelli, C. (2010). Counteracting depression and delinquency in late adolescence: The role of regulatory emotional and interpersonal self-efficacy beliefs. European Psychologist, 15, 34-48.

Carroll, A., Houghton, S., Wood, R., Unsworth, K., Hattie, J., Gordon, L., \& Bower, J. (2009). Self-efficacy and academic achievement in Australian high school students: The mediating effects of academic aspirations and delinquency. Journal of Adolescence, 32, 797-817.

Choi, N. (2004). Sex role group differences in specific, academic, and general self-efficacy. Journal of Psychology, 138, 149-159.

Distel, M. A., Middeldorp, C., Trull, T., Derom, C., Willemsen, G., \& Boomsma, D. (2011). Life events and borderline personality features: The influence of gene-environment interaction and gene-environment correlation. Psychological Medicine, 41, 849-860.

Farrell, A. D., Henry, D. B., Schoeny, M. E., Bettencourt, A., \& Tolan, P. H. (2010). Normative beliefs and selfefficacy for nonviolence as moderators of peer, school, and parental risk factors for aggression in early adolescence. Journal of Clinical Child \& Adolescent Psychology, 39, 800813.

Gigantesco, A., Stazi, M., Alessandri, G., Medda, E., Tarolla, E., \& Fagnani, C. (2011). Psychological well-being (PWB): A natural life outlook? An Italian twin study on heritability of PWB in young adults. Psychological Medicine December, 41, 2637-2649.

Greven, C. U., Harlaar, N., Kovas, Y., Chamorro-Premuzic, T., \& Plomin, R. (2009). More than just IQ: School achievement is predicted by self-perceived abilities - but for genetic rather than environmental reasons. Psychological Science, $20,753-762$.
Neale, M. C., \& Cardon, L. R. (1992). Methodology for genetic studies of twins and families. Dordrecht, Netherlands: Kluwer Academics.

Neale, M. C., Kendler, K. S., Hewitt, J. K., Silberg, J. L., Foley, D. L., \& Meyer, J. M. (1998). Assortative mating for major psychiatric diagnoses in two populationbased samples. Psychological Medicine, 28, 13891401.

Neale, M. C., Lubke, G., Aggen, S. H., \& Dolan, C. V. (2005). Problems with using sum scores for estimating variance components: Contamination and measurement noninvariance. Twin Research and Human Genetics, 8, 553568.

Neiss, M. B., Stevenson, J., Sedikides, C., Kumashiro, M., Finkel, E. J., \& Rusbult, C. E. (2005). Executive self, selfesteem, and negative affectivity: Relations at the phenotypic and genotypic level. Journal of Personality \& Social Psychology, 89, 593-606.

Nouwen, A., Urquhart Law, G., Hussain, S., McGovern, S., \& Napier, H. (2009). Comparison of the role of self-efficacy and illness representations in relation to dietary self-care and diabetes distress in adolescents with type 1 diabetes. Psychol Health, 24, 1071-1084.

Pastorelli, C., Caprara, G. V., Barbanelli, C., Rola, J., Rozsa, S., \& Bandura, A. (2001). The structure of children's perceived self-efficacy: A cross-national study. European Journal of Psychological Assessment, 17, 87-97.

Plomin, R., Asbury, K., \& Dunn, J. (2001). Why are children in the same family so different? Nonshared environment a decade later. Canadian Journal of Psychiatry, 46, 225233.

R Development Core Team. (2011). The R project for statistical computing. Accessed on $22^{\text {nd }}$ December, 2011. Retrieved from http://www.r-project.org.

Rijsdijk, F., \& Sham, P. (2002). Analytic approaches to twin data using structural equation models. Briefings in Bioinformatics, 3, 119-133.

Scholz, U., Doña, B. G., Sud, S., \& Schwarzer, R. (2002). Is general self-efficacy a universal construct? Psychometric findings from 25 countries. European Journal of Psychological Assessment, 18, 242-251.

Scourfield, J., Van den Bree, M., Martin, N., \& McGuffin, P. (2004). Conduct problems in children and adolescents - A twin study. Archives of General Psychiatry, 61, 489496.

South, S., \& Krueger, R. (2011). Genetic and environmental influences on internalizing psychopathology vary as a function of economic status. Psychological Medicine, 41, 107-117.

Steele, M. M., Daratha, K. B., Bindler, R. C., \& Power, T. G. (2011). The relationship between self-efficacy for behaviors that promote healthy weight and clinical indicators of adiposity in a sample of early adolescents. Health Education and Behavior, 38, 596-602.

Turkheimer, E., D’Onofrio, B. M., Maes, H. H., \& Eaves, L. J. (2005). Analysis and interpretation of twin studies, including measures of the shared environment. Child Development, 76, 1217-1233. 
van den Berg, S. M., Glas, C. A., \& Boomsma, D. I. (2007). Variance decomposition using an IRT measurement model. Behavior Genetics, 37, 604-616.

Waaktaar, T., \& Torgersen, S. (2012a). Genetic and environmental causes of variation in perceived loneliness in young people. American Journal of Medical Genetics Part B, 5, 580588.

Waaktaar, T., \& Torgersen, S. (2012b). Genetic and environmental causes of variation in trait resilience in young people. Behavior Genetics, 42, 366-377.
Widman, L., Golin, C., Grodensky, C., \& Suchindran, C. (2012). Do safer sex self-efficacy, attitudes toward condoms, and HIV transmission risk beliefs differ among men who have sex with men, heterosexual men, and women living with HIV? AIDS Behav, 1-10. doi: 10.1007/s10461-0110108-7.

Young, R. M., Gullo, M. J., Feeney, G. F., \& Connor, J. P. (2012). Development and validation of the Cannabis Refusal SelfEfficacy Questionnaire (CRSEQ) in adult cannabis users in treatment. Drug and Alcohol Dependence, 125, 244-251. 